Article

www.mdpi.com/journal/jlpea

\title{
An FSK and OOK Compatible RF Demodulator for Wake Up Receivers
}

\section{Thierry Taris ${ }^{1, *}$, Hassène Kraimia ${ }^{2}$, Didier Belot ${ }^{3}$ and Yann Deval ${ }^{1}$}

1 University of Bordeaux, IMS Lab, 341 Cours de la Liberation, Talence 33405, France;

\section{E-Mail:yann.deval@ims-bordeaux.fr}

2 BeSpoon, 17 rue du lac Saint André, 73372 Le Bourget du Lac, France; E-Mail: hkr@bespoon.com

3 CEA Leti, 17 av des Martyrs, 38000 Grenoble, France; E-Mail: didier.belot@cea.fr

* Author to whom correspondence should be addressed; E-Mail: Thierry.taris@ims-bordeaux.fr; Tel.: +33-540-002-769 (ext. 123); Fax: +33-556-371-545.

Academic Editor: Domenico Zito

Received: 23 April 2015 / Accepted: 4 November 2015 / Published: 30 November 2015

\begin{abstract}
This work proposes a novel demodulation circuit to address the implementation of Wake-Up Receivers (Wu-Rx) in Wireless Sensor Nodes (WSN). This RF demodulator, namely Modulated Oscillator for envelOpe Detection (MOOD), is compatible with both FSK and OOK/ASK modulation schemes. The system embeds an LC oscillator, an envelope detector and a base-band amplifier. To optimize the trade-off between RF performances and power consumption, the cross-coupled based oscillator is biased in moderate inversion region. The proof of concept is implemented in a $65 \mathrm{~nm}$ CMOS technology and is intended for the $2.4 \mathrm{GHz}$ ISM band. With a supply voltage of $0.5 \mathrm{~V}$, the demodulator consumes $120 \mu \mathrm{W}$ and demonstrates the demodulation of OOK and FSK at a data rate of $500 \mathrm{kbps}$.
\end{abstract}

Keywords: radio-frequency front-end; ultra low power; wake up receiver; demodulation

\section{Introduction}

The so-called Internet Of Things (IOT) aims the development of a smart environment that supports people in their daily lives. Essential to the implementation of IOT is the deployment of inter-connected, and dense Wireless Sensor Networks (WSN). Among the taught challenge in the ubiquitous development 
of WSN is the management of energy. Specifically, the reduction of the power consumption in wireless nodes concentrates a lot of attention due to their small form factors.

In WSN, the energy consumption of wireless communications dominates the overall power budget. To cope with this pitfall the Radio-Frequency (RF) transceiver of wireless nodes, Figure 1, is only turned on during data broadcasting. Out of these periods of communications, the RF transceiver is in sleep mode, and an auxiliary RF receiver, namely wake-up receiver ( $\mathrm{WuRx}$ ) in Figure 1, monitors the wireless channel for potential incoming traffic [1]. Since the WuRx is continuously listening, its active power consumption must be very low compared to the RF transceiver. Typically a budget of $100 \mu \mathrm{W}$ is allowed for WuRx [1]. To meet the requirement of ultra low power consumption, basic modulations such as OOK, FSK, or PSK, can be exploited for the wake up signals. Indeed the receiver architectures compatible with these modulation schemes are simple and allow power saving. The super-generative [2], tuned RF [3] or uncertain IF architectures [4] are popular solutions to demodulate an OOK modulated signal. In [3], the $\mathrm{Wu} R x$ consumes $51 \mu \mathrm{W}$ and achieves a sensitivity of $-64 \mathrm{dBm}$ at a data rate of 100 kbps to demodulate a $2400 \mathrm{MHz}$ OOK modulated signal. For FSK demodulation, WuRx are based on frequency discrimination architecture. In [5], the $\mathrm{Wu}$ Rx consumes $126 \mu \mathrm{W}$ and achieves a sensitivity of $-65 \mathrm{dBm}$ at a data rate of $20 \mathrm{kbps}$ to demodulate a $900 \mathrm{MHz}$ FSK modulated signal.

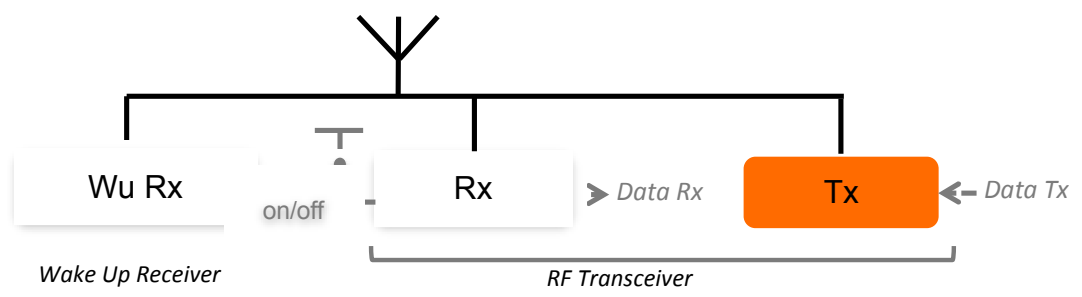

Figure 1. Radio module of a wireless sensor node.

The lack of regulation in WSN medium access opens up the choice for modulation in the wake up protocol. In practice, OOK and FSK signals are preferred but none of them really impose. The WuRx reported so far in the literature are compatible with only one of these two modulations. As a consequence, the WuRx architecture implemented in wireless nodes can limit the interoperability of WSNs. This work proposes a novel low power demodulator compatible with both OOK and FSK modulations. The principle of a dual mode demodulation is first exposed in Section 2. The proof of concept, detailed in Section 3, features an LC oscillator coupled with an envelope detector implemented in a $65 \mathrm{~nm}$ CMOS technology. The characterization of the MOdulated Oscillator for envelope Detection (MOOD) receiver is further presented in Section 4. The circuit consumes $120 \mu \mathrm{W}$, and properly demodulates OOK and FSK modulated signal at $2.4 \mathrm{GHz}$ with data rate up to $500 \mathrm{kbps}$.

\section{Principle of Frequency and Amplitude Demodulation with an LC Oscillator}

The principle of frequency demodulation exploited in this work is first exposed. The response of a resonator oscillator in pulled and locked modes is analyzed the second time. It is demonstrated that an external frequency modulated signal is transformed into an amplitude-modulated signal when the oscillator is in pulled mode. In locked mode, an external amplitude modulated signal is transferred to the output with a maximum voltage swing. 


\subsection{Non-Coherent Demodulation of a Frequency Modulated Signal}

The binary Frequency Shift Keying (FSK) is a frequency modulation commonly exploited in wireless sensor networks. The data are transmitted shifting the frequency of a continuous carrier between $\mathrm{f}_{1}$ and $\mathrm{f}_{2}$ as illustrated in Figure 2.

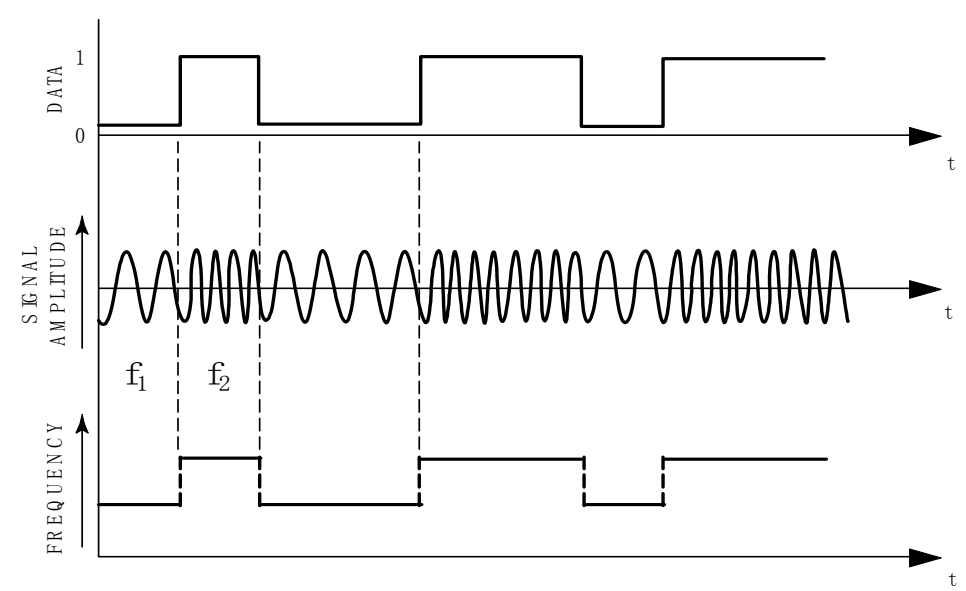

Figure 2. Principle of binary FSK modulations.

The non-coherent demodulation of a binary FSK modulated signal can be performed by frequency discrimination as depicted in Figure 3. This approach is interesting for power saving. Two parallel chains select one of the two frequencies, $\mathrm{f}_{1}$ or $\mathrm{f}_{2}$, and extract the amplitude of the signal by envelope detection. The data are then constructively generated by comparison of $V_{a m p}(t)$ and $V_{a m p 1}(t)$ signals. The frequency deviation, which is the shift between the two discrete frequencies $f_{1}$ and $f_{2}$, is usually in the range of few tens to few hundreds of $\mathrm{kHz}$. As a consequence, the implementation of the circuits which perform the frequency selection is difficult, expensive and sensitive to process variations in the RF domain. For this reason, the FSK demodulation by frequency discrimination is not exploited in WSN applications.

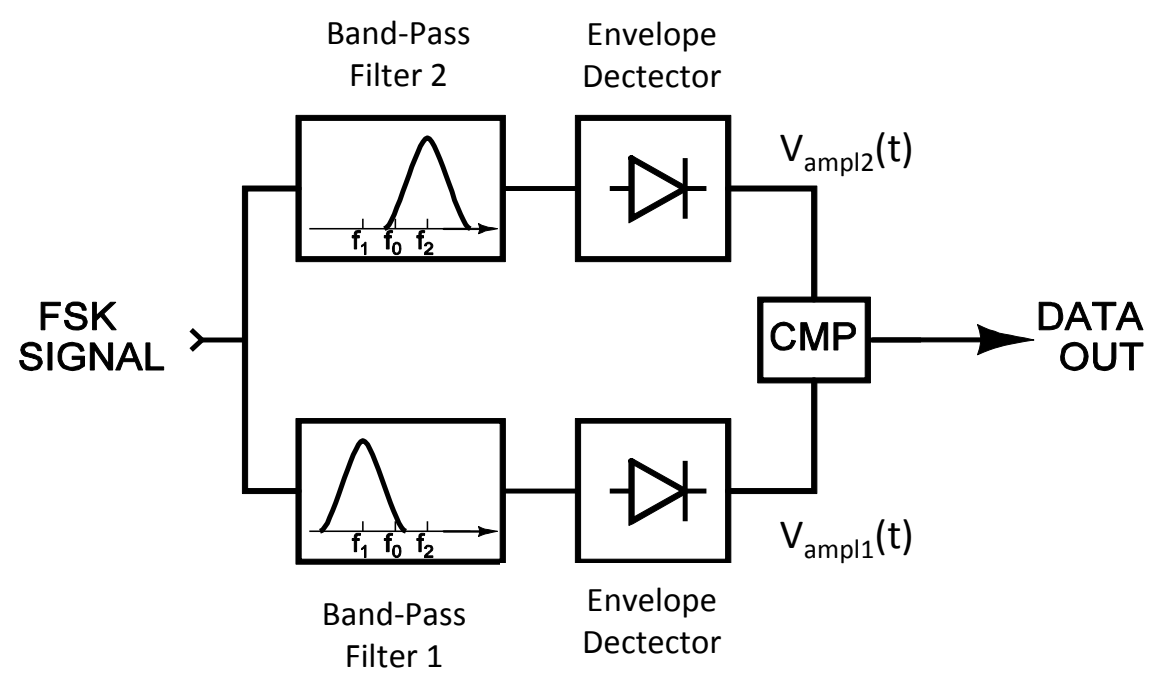

Figure 3. Non-coherent FSK demodulator. 
We propose a new architecture for non-coherent demodulation that circumvents the selectivity limitation of the filter-type demodulator. It requires a frequency to amplitude conversion block and an envelope detector as illustrated in Figure 4.

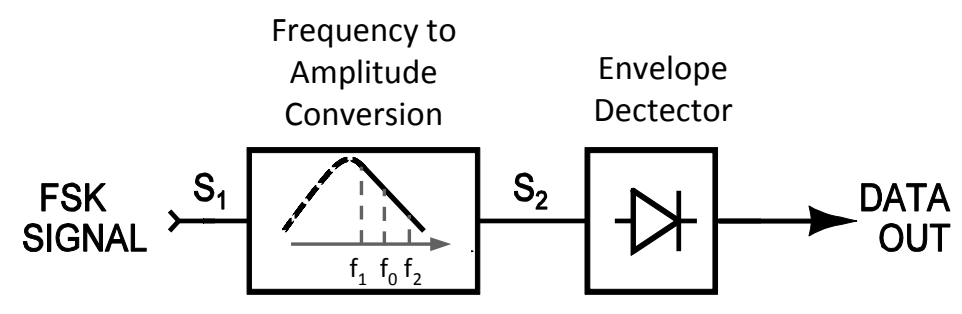

Figure 4. Proposed FSK demodulator.

To limit the bandwidth of the receiver, it is convenient to use a frequency to amplitude conversion block with a frequency response of band-pass type as illustrated in Figure 4. The bandwidth of the band-pass block contains the carrier $\mathrm{f}_{0}$, and the two frequencies $\mathrm{f}_{1}$ and $\mathrm{f}_{2} . \mathrm{f}_{1}$ and $\mathrm{f}_{2}$ are located in the roll-off response of the band-pass block which yields a different attenuation for each frequency. Hence, the frequency shift of the incoming FSK signal, $\mathrm{S}_{1}$, is transformed into amplitude variations in $\mathrm{S}_{2}$. The data are extracted from $\mathrm{S}_{2}$ with an envelope detector. This signal processing of the FSK signal is illustrated in Figure 5. Since the proposed principle of demodulation is no longer based on frequency discrimination but frequency to amplitude conversion, the constrain on the filter selectivity is relaxed in comparison with the demodulator of Figure 3. One condition to perform the FM to AM transformation is to keep the frequency fo, in Figure 4, different to the center frequency of the frequency to amplitude conversion block.

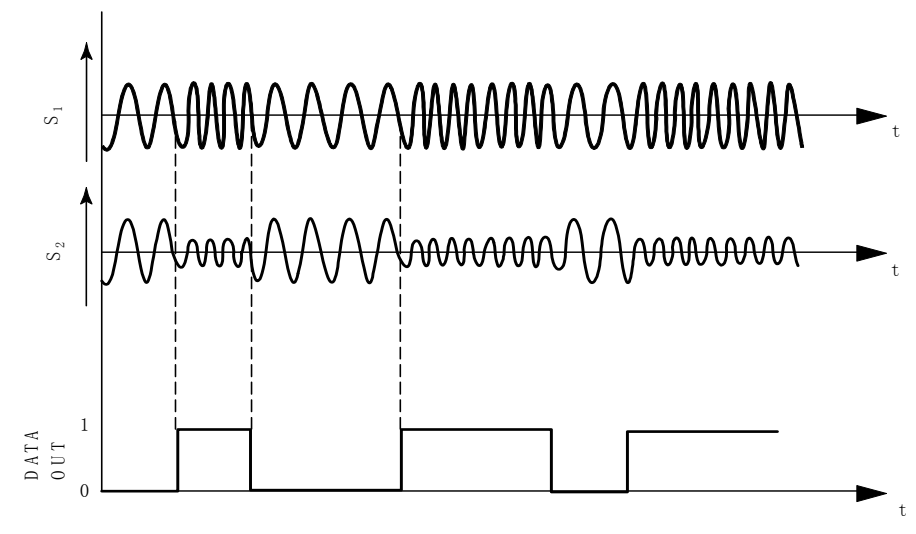

Figure 5. Time evolution of the received signal with the proposed architecture.

The relaxed selectivity for the band-pass filter and the single signal path processing of the proposed architecture significantly reduce the complexity, the power dissipation and the cost of implementation compared to a classical filter-type FSK demodulator. Another attractive aspect of the proposed demodulator is its compatibility with amplitude modulation. Indeed, an AM signal will be naturally demodulated by the system since the envelope of the incoming signal is already non-constant. Furthermore, this AM demodulation occurs with no condition on the signal carrier frequency until it is in the bandwidth of the frequency to amplitude conversion block. 


\subsection{AM-to-FM Conversion and AM-AM Transfer with an LC Oscillator}

The critical block of the demodulation principle presented in Figure 3 is the frequency to amplitude converter. A band-pass filter with a steep slope rejection would be attractive, but it is not compatible with silicon integration. Another option is to perform the conversion with an LC Voltage Controlled Oscillator (LC-VCO). This popular block of RF transceivers exhibits a band-pass behavior and allows a center frequency tuning. Interestingly, the oscillating frequency of the LC-VCO can be adjusted to be different to the center frequency of the FSK modulated signal to ensure FM to AM conversion. However, in the presence of an injected signal, an LC oscillator can be either locked or pulled, depending on the magnitude of the perturbation. The response of an LC oscillator in these two modes of operation needs to be investigated to go further in the implementation of the concept proposed in Figure 4.

The phenomenon of injection [6], is a fundamental property of oscillators. Among the most famous contributions to its study are the theory of Adler [7], the theory of Kurokawa [8] and complementary study exposed in [9-11]. When an external periodic signal is mixed to an oscillator, the system can be locked or pulled. In locked mode, the oscillator tracks the injected signal. Depending on the ratio of the incident signal frequency to the oscillation frequency, different methods of injection locking are possible: fundamental, sub-harmonic and super-harmonic. In the first case, the injected frequency is the same as the oscillation frequency, in the other two cases the injected frequency is respectively a sub-harmonic or $n$ th-harmonic of the oscillation frequency. If the injected signal frequency is out of the locking range, the oscillator is pulled (instead of locked) by the external signal. To further investigate the oscillator response in injection modes, we consider the behavioral model proposed in Figure 6 . The tank $Z(\omega)$ resonates at a frequency $\omega_{0}$, the ideal inverting amplifier, in the feedback path, ensures a close loop gain of unity and a total phase shift of $2 \pi$.

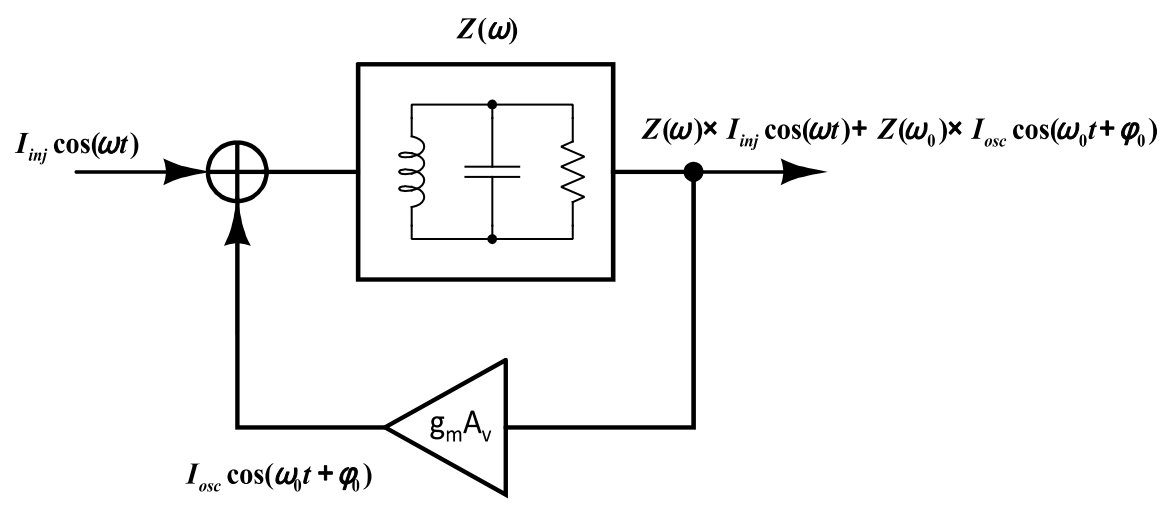

Figure 6. Simplified behavioral model for injection pulled oscillator.

\subsubsection{Injection of a FM Signal}

If the amplitude and frequency of $\mathrm{I}_{\text {inj }}$ (Figure 6) are properly chosen, the circuit keeps on oscillating at $\omega_{0}$ and injection pulling occurs. Under this condition, the output voltage contains both the injected signal and the free-running oscillation. To derive the analytic expressions of the output voltage under the injection of a modulated signal, we assume the simplified expression (Equation (1)) for the tank impedance. 


$$
Z(\omega) \cong \frac{R_{p}}{1+j 2 Q \frac{\omega-\omega_{0}}{\omega_{0}}}
$$

With $\left(1 / R_{p}\right)$ the tank losses and Q the tank quality factor. For the first case of study, we consider an injected FM signal IFM Equation (2):

$$
I_{\text {Inj }}(t)=I_{F M}(t)=I_{0} \cos \left[\left(\omega_{c} t\right)+\beta \cdot \sin \left(\omega_{m} t\right)\right]
$$

where $\omega_{\mathrm{c}}$ and $\omega_{\mathrm{m}}$ are respectively the carrier frequency and modulating frequency, $\beta$ is the modulation index. The instantaneous phase and pulsation are derived as it follows:

$$
\begin{gathered}
\varphi(t)=\left(\omega_{c} t\right)+\beta \sin \left(\omega_{m} t\right) \\
\varphi(t)=\frac{d \varphi(t)}{d t}=\omega_{c}+\beta \omega_{m} \cos \left(\omega_{m} t\right)
\end{gathered}
$$

Combining Equations (1) and (2), the output voltage can be expressed as a superposition of the injected signal and the free-running oscillation:

$$
\begin{gathered}
V_{\text {out }}(t)=V_{\text {Inj }}(t)+V_{\text {osc }}(t) \\
V_{\text {out }}(t)=Z(\omega) \times I_{0} \cos \left[\left(\omega_{c} t\right)+\beta \sin \left(\omega_{m} t\right)\right]+Z\left(\omega_{0}\right) \times I_{\text {osc }} \cos \left[\left(\omega_{0} t\right)+\phi_{0}\right]
\end{gathered}
$$

Let us focus now on the module of the output signal $\mathrm{V}_{\text {out: }}$

$$
\left|V_{\text {out }}\right|=\left|Z(\omega) \times I_{0} \cos \left[\left(\omega_{c} t\right)+\beta \sin \left(\omega_{m} t\right)\right]+Z\left(\omega_{0}\right) \times I_{\text {osc }} \cos \left[\left(\omega_{0} t\right)+\phi_{0}\right]\right|
$$

With respect to the triangular inequality, we have:

$$
\begin{gathered}
\left|\mathrm{V}_{\text {out }}\right| \leq\left|\mathrm{Z}(\omega) \times \mathrm{I}_{0} \cos \left[\left(\omega_{\mathrm{c}} \mathrm{t}\right)+\beta \sin \left(\omega_{\mathrm{m}} \mathrm{t}\right)\right]\right|+\left|\mathrm{Z}\left(\omega_{0}\right) \times \mathrm{I}_{\text {osc }} \cos \left[\omega_{0} \mathrm{t}+\phi_{0}\right]\right| \\
\left|\mathrm{V}_{\text {out }}\right| \leq\left|\mathrm{Z}(\omega) \times \mathrm{I}_{0}\right|+\left|\mathrm{Z}\left(\omega_{0}\right) \times \mathrm{I}_{\text {osc }}\right| \\
\left|\mathrm{V}_{\text {out }}\right| \leq \mathrm{R}_{\mathrm{p}}\left[\mathrm{I}_{\text {osc }}+\frac{\mathrm{I}_{0}}{\sqrt{1+4 \mathrm{Q}^{2}\left(\frac{\omega-\omega_{0}}{\omega_{0}}\right)^{2}}}\right]
\end{gathered}
$$

The second term in Equation (9) highlights that the module of the output voltage is modulated by the instantaneous frequency (or pulsation $\omega(\mathrm{t})$ in Equation (4)) of the injected FM signal. A pulled oscillator transforms a frequency modulated signal into an amplitude modulated signal. The signal's envelope contains the data that will be further extracted by an envelope detector.

We consider now the situation of an injected FM signal locking the oscillator. The circuit oscillates at $\omega_{c}$ instead of $\omega_{0}$ because the injection locking occurs. Under this condition, the output voltage $\left(\mathrm{V}_{\text {out }}\right)$ and the injected current ( $\left.\mathrm{I}_{\text {Inj }}\right)$ must bear a phase difference $\varphi_{\text {out }}$ and satisfy the conditions of Equation (10):

$$
V_{\text {out }} \cos \left(\omega_{c} t+\phi_{\text {out }}\right)=\left[I_{0} \cos \left[\left(\omega_{c} t\right)+\beta \sin \left(\omega_{\mathrm{m}} \mathrm{t}\right)\right]+\mathrm{I}_{\text {osc }} \cos \left[\left(\omega_{\mathrm{c}} \mathrm{t}\right)+\phi_{\text {out }}\right]\right] \times \mathrm{Z}(\omega)
$$

With the complex exponential notation and after some simplifications, Equation (10) becomes: 


$$
\mathrm{V}_{\text {out }}\left(1+\mathrm{j} 2 \mathrm{Q} \frac{\omega_{\mathrm{c}}-\omega_{0}}{\omega_{0}}\right)=\mathrm{R}_{\mathrm{p}}\left(\mathrm{I}_{\text {osc }}+\mathrm{I}_{0} \mathrm{e}^{\mathrm{j}\left[\beta \sin \left(\omega_{\mathrm{m}} \mathrm{t}\right)-\phi_{\text {out }}\right]}\right)
$$

Equation (11) can be separated into real and imaginary parts leading to:

$$
\begin{gathered}
\text { Real Part } \mathrm{V}_{\text {out }}=\mathrm{R}_{\mathrm{p}}\left[\mathrm{I}_{\text {osc }}+\mathrm{I}_{0} \cos \left(\beta \sin \left(\omega_{\mathrm{m}} \mathrm{t}\right)-\phi_{\text {out }}\right)\right] \\
\text { Imaginary Part } \sin \left[\beta \sin \left(\omega_{\mathrm{m}} \mathrm{t}\right)-\phi_{\text {out }}\right]=\frac{2 \mathrm{Q}}{\mathrm{I}_{0}} \frac{\mathrm{V}_{\text {out }}}{\mathrm{R}_{\mathrm{p}}} \frac{\omega_{\mathrm{c}}-\omega_{0}}{\omega_{0}}
\end{gathered}
$$

The expression (Equation (12a)) provides the output amplitude where as Equation (12b) gives the output phase as a function of the injected signal frequency. Substituting $V_{\text {out }}$ Equation (12a) in Equation (12b) the oscillator locking range can be derived according [6,9], it is reported in Equation (13).

$$
\frac{\left|\omega_{\mathrm{c}}-\omega_{0}\right|}{\omega_{0}} \leq \frac{1}{2 \mathrm{Q}} \frac{\mathrm{I}_{0}}{\mathrm{I}_{\mathrm{osc}}} \text { with } \mathrm{I}_{0} \ll \mathrm{I}_{\mathrm{osc}}
$$

Under locking conditions, the amplitude of $\mathrm{V}_{\text {out }}$ Equation (12a) is not modulated by the instantaneous frequency of the injected FM signal. As a consequence, the FM-to-AM conversion does not occur, and the demodulation of an FM signal is not possible.

\subsubsection{Injection of an AM Signal}

The expression of an amplitude-modulated signal is proposed in Equation (14). The behavior of the oscillator in pulled and locked mode is investigated under the injection of an AM signal.

$$
I_{\text {Inj }}(t)=I_{A M}(t)=I_{0}\left[1+\alpha \cos \left(\omega_{m} t\right)\right] \sin \left(\omega_{c} t\right)
$$

where $\omega_{\mathrm{c}}$ and $\omega_{\mathrm{m}}$ are respectively the carrier frequency and modulating frequency, $\alpha$ is the modulation index.

This study figures out the property of the AM modulated signal-i.e., the envelope variations-is naturally transferred to the output signal delivered by the oscillator. The maximum amplitude of the output voltage $\mathrm{V}_{\text {out }}$ is derived under pulling condition in Equation (15) and locking injection in Equation (16). A maximum amplitude is obviously achieved when the oscillator is locked.

$$
\begin{array}{r}
\left|\mathrm{V}_{\text {out }}\right|_{\text {AM,Pulling }} \leq \mathrm{R}_{\mathrm{p}}\left[\mathrm{I}_{\text {osc }}+\frac{\mathrm{I}_{0}(1+|\alpha|)}{\sqrt{1+4 \mathrm{Q}^{2}\left(\frac{\omega-\omega_{0}}{\omega_{0}}\right)^{2}}}\right] \\
\left|\mathrm{V}_{\text {out }}\right|_{\text {AM }, \text { Locking }} \leq \mathrm{R}_{\mathrm{p}}\left[\mathrm{I}_{\text {osc }}+\mathrm{I}_{0}(1+|\alpha|)\right]
\end{array}
$$

To relax the constraint on filter selectivity in conventional non-coherent FSK demodulators (Figure 3), the principle of a novel demodulator has been proposed in Figure 4. To make it compatible with system on-chip integration, an LC oscillator is further studied to perform the frequency to amplitude conversion. These investigations on the behavior of a LC oscillator, in the presence of an external modulated signal, highlight the conditions of operation for FM and AM demodulation. In pulled mode, the LC oscillator converts an FM input signal, $\mathrm{S}_{1}$ in Figure 4, into an AM output signal $\mathrm{S}_{2}$. The data are 
transferred in the envelope of $\mathrm{S}_{2}$, and extracted by an envelope detector. In locked mode, the frequency to amplitude conversion does not occur, the demodulation of an FM signal is not possible in such a mode. In the case of an AM injected signal $\mathrm{S}_{1}$, it is transferred to $\mathrm{S}_{2}$ with a maximum amplitude in locked mode, the data are then demodulated by envelope detection.

\section{Implementation of a MOOD Demodulator}

The demodulator architecture presented in Figure 7, namely Modulated Oscillator for Envelope Detection (MOOD), exploits the principle of demodulation proposed in Figure 4. It may be viewed as a Tuned RF receiver, where an LC oscillator is introduced before the envelope detector to perform an FM-to-AM conversion. It has been demonstrated this demodulation circuit is theoretically compatible with frequency and amplitude modulation schemes. As a proof of concept, this MOOD system is implemented in a $65 \mathrm{~nm}$ CMOS technology from ST Microelectronics, and is intended for $2.4 \mathrm{GHz}$ ISM Band. This section further details the design strategy and the characterization of the main blocks featuring a MOOD receiver: the LC oscillator and the envelope detector.

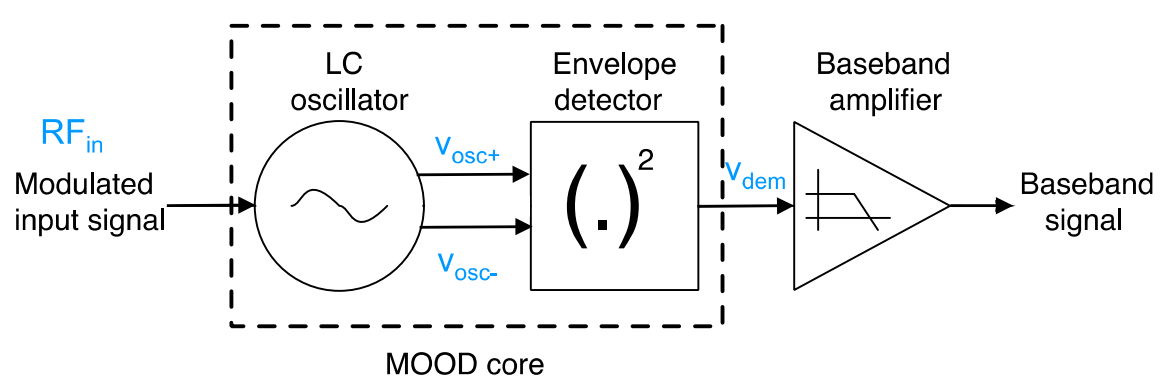

Figure 7. Simplified behavioral model for injection pulled oscillator.

\subsection{Low Power LC Oscillator}

LC oscillators are very popular in wireless transceivers as they achieve a low phase noise due to the high energy-storage capability of LC tanks. A standard cross-coupled architecture is selected here for its immunity to supply common-mode disturbances. The schematic of the oscillator is presented in Figure $8 \mathrm{a}$ and the device sizes are reported in Figure $8 \mathrm{~b}$. The tank, formed by $\mathrm{L}_{\text {tank }}$ and $\mathrm{C}_{\text {tank, }}$, sets the free running oscillation of the oscillator, which is fine tuned by $\mathrm{C}_{\text {var. }}$. The cross-coupled pair $\left(\mathrm{M}_{2 \mathrm{a}}, \mathrm{M}_{2 \mathrm{~b}}\right)$ compensates for the loss of the tank and sustains the oscillation. The transistors $\mathrm{M}_{2 \mathrm{i}}$ are sized to operate in moderate inversion region to achieve a best trade-off between performances and current consumption according [12]. The transistor $\mathrm{M}_{1}$ steers the tail current and injects the external signal $\mathrm{RF}_{\text {in }}$ applied to its gate. The inductors $\mathrm{Lg}_{\mathrm{g}}$ and $\mathrm{L}_{\mathrm{s}}$ perform the $50 \Omega$ input matching. A micrograph of the oscillator, implemented for a stand-alone characterization, is presented in Figure 8c. 


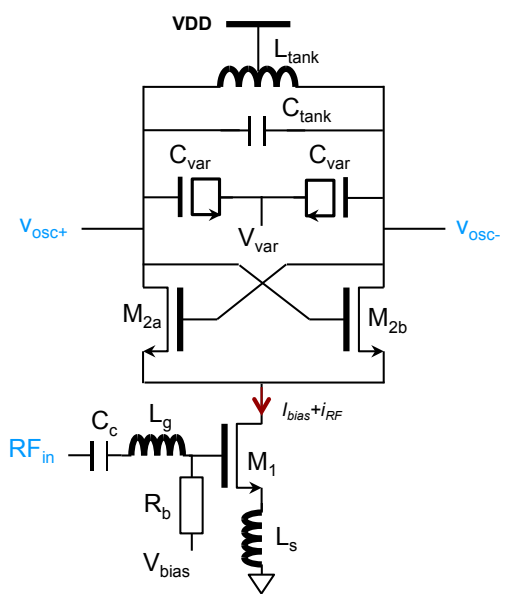

(a)

\begin{tabular}{cc}
\hline Device & Size \\
\hline $\mathrm{M}_{1}(\mathrm{~W} / \mathrm{L})$ & $(20 / 0.06) \mathrm{um}$ \\
$\mathrm{M}_{2}(\mathrm{~W} / \mathrm{L})$ & $(20 / 0.06) \mathrm{um}$ \\
$\mathrm{L}_{\text {tank }}$ & $6 \mathrm{nH}$ \\
$\mathrm{C}_{\text {tank }}$ & $530 \mathrm{fF}$ \\
$\mathrm{C}_{\mathrm{var}}$ & $(5 / 1) \mathrm{um}$ \\
$\mathrm{L}_{\mathrm{g}}$ & $5.8 \mathrm{nH}$ \\
$\mathrm{L}_{\mathrm{s}}$ & $1.2 \mathrm{nH}$ \\
$\mathrm{R}_{\mathrm{b}}$ & $5 \mathrm{k} \Omega$ \\
$\mathrm{C}_{\mathrm{c}}$ & $5 \mathrm{pF}$ \\
\hline
\end{tabular}

(b)

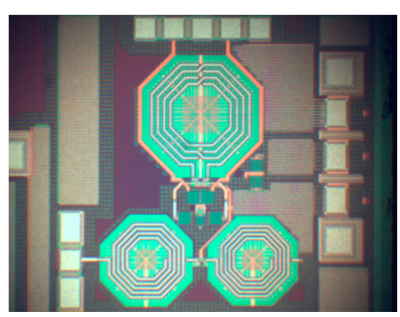

(c)

Figure 8. Schematic of an LC cross-coupled oscillator with RF injection (a); device size (b); micrograph of the oscillator $(\mathbf{c})$.

The tuning range of the oscillator is presented in Figure 9a. The free running frequency is centered to $2.48 \mathrm{GHz}$, it can be adjusted from $2.43 \mathrm{GHz}$ to $2.54 \mathrm{GHz}$. The phase noise (PN) is measured at $1 \mathrm{MHz}$ from the carrier for different bias currents, Figure $9 \mathrm{~b}$. A minimum $\mathrm{PN}$ of $-100 \mathrm{dBc} / \mathrm{Hz}$ is achieved at $400 \mathrm{uA}$. Below this value, the oscillator operates in current limited mode, the PN increases with the decrease of the current. Above $400 \mu \mathrm{A}$, the PN regrows as the oscillator operates in voltage limited mode. The oscillator is further exploited in a low power mode, and the bias current is fixed to $248 \mu \mathrm{A}$. The performances of the oscillator are reported in Figure 9c for these conditions of operation.

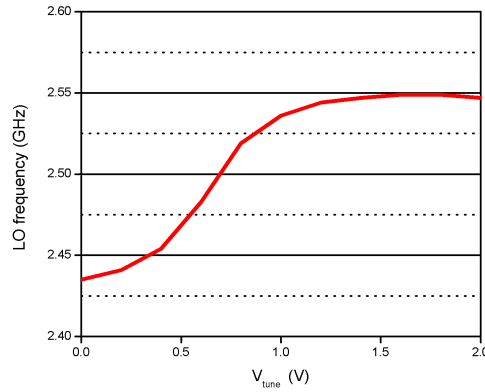

(a)

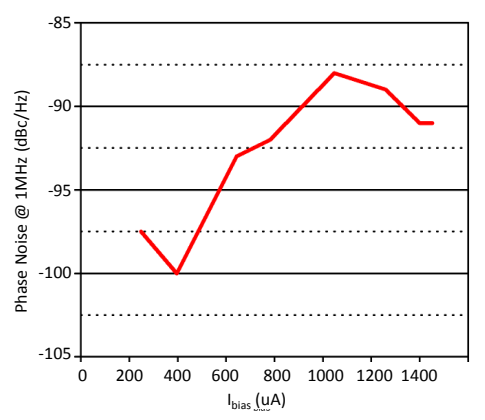

(b)

\begin{tabular}{|c|c|}
\hline VDD/ $/ \mathbf{P}_{\text {diss }}$ & $\mathbf{0 , 5 V / 1 2 4 ~ u W ~}$ \\
\hline $\mathrm{f}_{0}$ & $2.48 \mathrm{GHz}$ \\
\hline Tuning Range & {$[2.43-2.54] \mathrm{GHz}$} \\
\hline $\mathrm{P}_{\text {out }}$ & $-19 \mathrm{dBm}$ \\
\hline $\begin{array}{c}\text { Phase Noise } \\
@ 1 \mathrm{MHz}\end{array}$ & $-98.5 \mathrm{dBc} / \mathrm{Hz}$ \\
\hline $\mathrm{R}_{\mathrm{b}}$ & $5 \mathrm{k} \Omega$ \\
\hline $\mathrm{C}_{\mathrm{c}}$ & $5 \mathrm{pF}$ \\
\hline
\end{tabular}

(c)

Figure 9. Oscillator Tuning Range versus $\mathrm{V}_{\text {tune }}(\mathbf{a})$; Phase Noise at $1 \mathrm{MHz}$ versus bias current (b) Oscillator performances at VDD $=0.5 \mathrm{~V}$; \& $\mathrm{I}_{\text {bias }}=248 \mu \mathrm{A}$ (c).

The two modes of operation, which will be further exploited in a MOOD receiver are pulled mode for FM to AM conversion and locked mode for AM to AM transfer. They are first characterized on the stand-alone $2.4 \mathrm{GHz}$ LC-oscillator. To study the response in pulled mode, a continuous wave (CW) signal of $-31 \mathrm{dBm}$ is applied at the input node RFin (Figure 8a). The output power of the oscillator, Pout, is represented in Figure 10a as a function of $\Delta \mathrm{f}$, which is the deviation between the frequency of the $\mathrm{CW}$ signal and the free running frequency of the oscillator. For large frequency deviations, the output spectrum follows the free running response as it operates in pulled mode. Figure 10b represents the maximum FM to AL conversion gain (CGFM-AM) of the oscillator in pulled mode. The figures, extracted 
from Figure 10a, are valid for a frequency shift of the FM signal equals to half of the corresponding frequency deviation $\Delta \mathrm{f}$. CGFM-Am strongly depends on the quality factor of the resonator, and it dramatically decreases when $\Delta \mathrm{f}$ exceeds $50 \mathrm{MHz}$. Within a frequency range of $2 \mathrm{MHz}$ centered to the free running frequency, the oscillator is locked. The minimum power required to lock the oscillator is measured, and represented in Figure $10 \mathrm{~b}$ for different $\Delta \mathrm{f}$. We can note the smaller the frequency deviation, the lower is the power required to lock the oscillator. At a $\Delta \mathrm{f}=20 \mathrm{MHz}$, a minimum power of $-15 \mathrm{dBm}$ is needed to lock the oscillator, for larger frequency deviations the locking power linearly increases with $\Delta \mathrm{f}$ with a slope of $0.25 \mathrm{~dB} / \mathrm{MHz}$. This analysis figures out that the sensitivity of a MOOD demodulator operating in locking mode is improved when the free running frequency of the oscillator is tuned to the carrier frequency of the incoming AM signal.

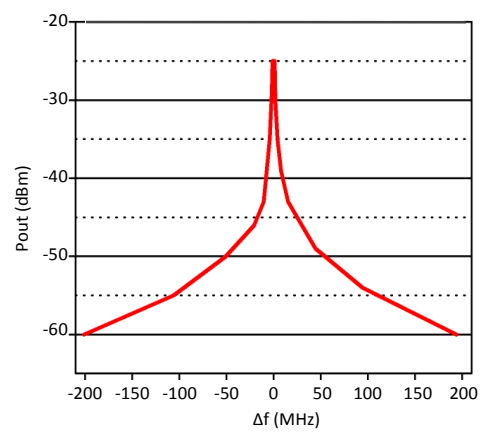

(a)

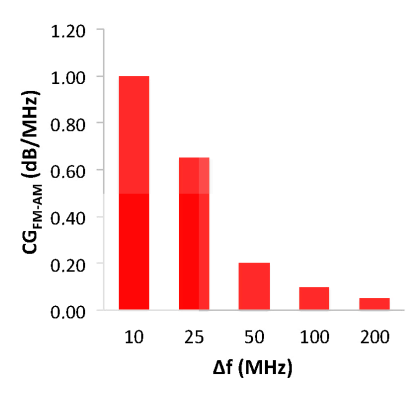

(b)

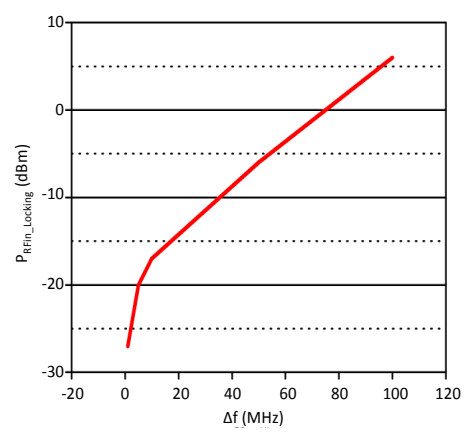

(c)

Figure 10. $P_{\text {out }}$ in $\mathrm{dBm}$ versus $\Delta \mathrm{f}=\left|\mathrm{f}_{\mathrm{LO}}-\mathrm{f}_{\mathrm{RF}}\right|$ with $\mathrm{P}_{\mathrm{RFin}}=-31 \mathrm{dBm} \& \mathrm{fLO}_{\mathrm{LO}}=2.48 \mathrm{GHz}$ (a); FM to AM Conversion Gain (b); $P_{\text {RFin }}$ to lock the oscillator versus $\Delta \mathrm{f}=\left|\mathrm{f}_{\mathrm{LO}}-\mathrm{f}_{\mathrm{RFin}}\right|(\mathbf{c})$.

\subsection{Envelope Detector Design}

An envelope detector (ED) provides a simple and very low power solution to extract the data embedded in the amplitude of a signal. This detection circuit can be implemented using any non-linear element, such as a diode. However, in the CMOS process, it is convenient to use MOS transistors to perform the detection. The schematic of the envelope detector, included in the MOOD demodulator of Figure 7, is presented in Figure 11a. A single-ended version of the circuit, Figure 11b,c, has been implemented for characterization.

The ED reported in Figure 11 is a CMOS version of the standard bipolar topology described in [13], and is basically a band-limited source follower. The operation of the circuit is similar to the bipolar version if the device $\mathrm{M}_{1}$ is biased in weak inversion, as the drain current of a MOS transistor is an exponential function of gate-source voltage in this region. $\mathrm{M}_{2}$ acts as a simple current source to bias $\mathrm{M}_{1}$ with a constant current. A large capacitor $C_{f}$ is connected to node $V_{\text {out }}$. The bandwidth at the output is derived in Equation (17). It is set by the pole $\mathrm{f}_{\mathrm{p} \text {,det }}$ formed by $\mathrm{C}_{\mathrm{f}}$, and the output impedance of the detector which is approximately $\left(1 / \mathrm{g}_{\mathrm{m} 1}\right)$ neglecting the body effect:

$$
\mathrm{f}_{\mathrm{p}, \mathrm{det}}=\frac{\mathrm{g}_{\mathrm{m} 1}}{2 \pi \mathrm{C}_{\mathrm{f}}}
$$

This pole is designed to be low enough to filter out any signal at the fundamental and higher harmonics but still affords enough bandwidth to avoid the attenuation of the baseband signal. 
For a typical OOK signal, the detected baseband waveform is a square wave, $f_{p}$,det is adjusted to twice the maximum data rate of the demodulated signal.

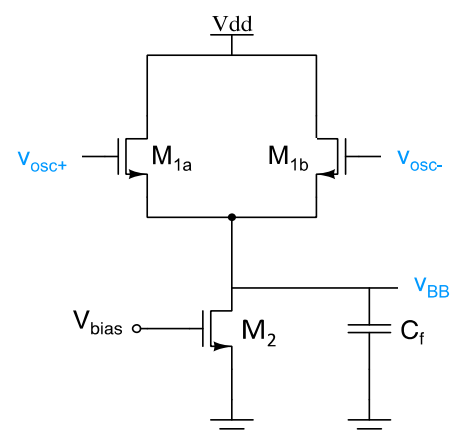

(a)

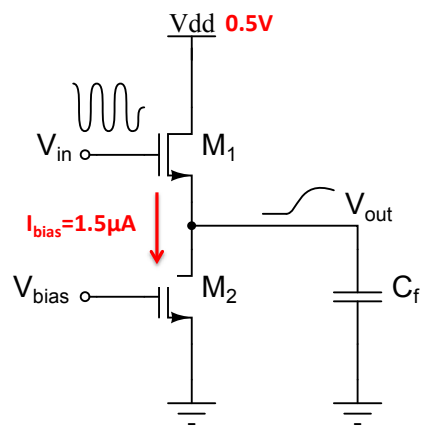

(b)

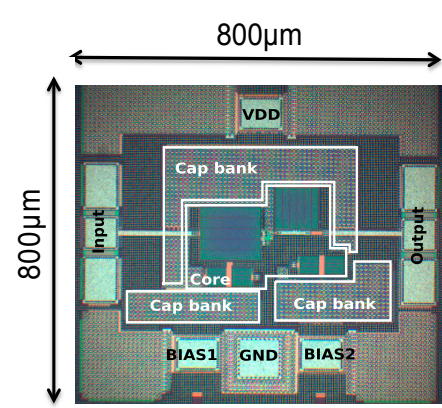

(c)

Figure 11. Differential ED implemented in the MOOD demodulator (a); single ED implemented as a standalone circuit for characterization (b); micrograph of the single ended ED in $65 \mathrm{~nm}$ CMOS (c).

An AC input signal is applied to the input, $V_{\text {in }}$ in Figure $11 \mathrm{~b}$. Since the output bandwidth is much smaller than the input signal frequency, the full signal appears across the gate-source terminal $\mathrm{V}_{\mathrm{GS}}$ of $\mathrm{M}_{1} . \mathrm{M}_{1}$, biased in WI region, generates an output current that is an exponential function of the input voltage. To further investigate the circuit of Figure 11b, an equivalent model is proposed in Figure 12. The exponential function, expanded with Taylor series and dropping terms above the second order, acts as a squaring function. It actually transforms the $\mathrm{AC}$ amplitude of $\mathrm{V}_{\text {in }}$ into a $\mathrm{DC}$ current $\mathrm{i}_{0}$. The fundamental frequency, along with higher order harmonics, of $\mathrm{V}_{\mathrm{in}}$ will be filtered out by $\mathrm{C}_{\mathrm{f}}$. Although higher order terms will also generate DC components, these contributions are small compared to the squaring term. The output impedance $\mathrm{R}_{\mathrm{o}}$ is simply $1 / \mathrm{g}_{\mathrm{m} 1}$.

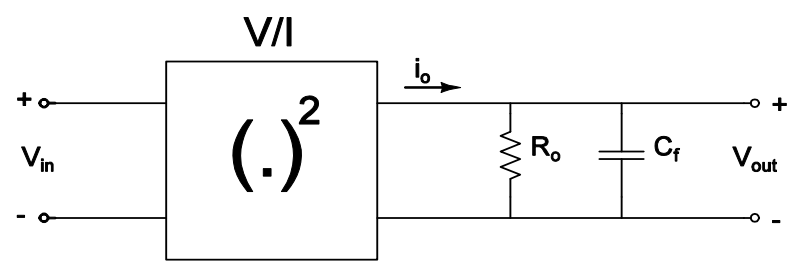

Figure 12. Simple model of envelope detector to calculate conversion gain.

Referring to Figure $11 \mathrm{~b}$, the large signal drain current of $\mathrm{M}_{1}$ operating in weak inversion is modeled as [14]:

$$
\mathrm{I}_{\mathrm{D}} \approx \mathrm{I}_{0}^{\prime} \exp \left(\frac{\mathrm{V}_{\mathrm{GS}}-\mathrm{V}_{\text {th }}}{\mathrm{nV}_{\mathrm{t}}}\right)
$$

where I' 0 is a constant depending on process and device size, $V_{t h}$ is the threshold voltage, $V_{t}$ is the thermal voltage (kT/q), and $\mathrm{n}$ is the subthreshold slope factor. Expanding Equation (18) in Taylor series and focusing on the second order term, the DC component $i_{0}$ of $I_{D}$ is expressed in Equation (19): 


$$
\mathrm{i}_{0}=\frac{\mathrm{V}_{\mathrm{in}}^{2}}{2} \frac{\mathrm{I}_{\mathrm{D}}}{\left(\mathrm{nV} \mathrm{V}_{\mathrm{t}}\right)^{2}}
$$

Substituting for $V_{i n}$, the expression of a sine wave $\left(V_{s} \sin \left(\omega_{s} t\right)\right)$ with $g_{m}=I_{D} / n V_{t}$, the DC component io, Figure 17, becomes:

$$
\mathrm{i}_{0}=\frac{\mathrm{g}_{\mathrm{m}}}{2 \mathrm{nV} \mathrm{V}_{\mathrm{t}}} \mathrm{V}_{\mathrm{s}}^{2}\left(\frac{1-\cos \left(2 \omega_{\mathrm{s}} \mathrm{t}\right)}{2}\right)
$$

The second harmonic term in Equation (20) is filtered out by the detector output pole $\mathrm{f}_{\mathrm{p}, \mathrm{det}}$, and the output voltage of the detector $\mathrm{V}_{\text {out }}$ is expressed as Equation (21):

$$
\mathrm{V}_{\text {out }}=\mathrm{i}_{0} \mathrm{R}_{0}=\frac{\mathrm{i}_{0}}{\mathrm{~g}_{\mathrm{m}}}=\frac{\mathrm{V}_{\mathrm{s}}^{2}}{4 \mathrm{nV}}
$$

The conversion gain of the detector, $\mathrm{GC}_{\text {det, }}$, is finally the ratio of the output $\mathrm{DC}$ voltage $\mathrm{V}_{\text {out }}$ to the peak AC amplitude $\mathrm{V}_{\mathrm{s}}$ of $\mathrm{V}_{\text {in: }}$ :

$$
\mathrm{GC}_{\text {det }}=\frac{\mathrm{V}_{\text {out }}}{\mathrm{V}_{\mathrm{s}}}=\frac{\mathrm{V}_{\mathrm{s}}}{4 \mathrm{n} \mathrm{V}_{\mathrm{t}}}
$$

The measurement results of the single-ended detector are reported in Figure 13. The circuit consumes $2 \mu \mathrm{W}$ for a VDD of $0.5 \mathrm{~V}$. The frequency response of the detector, Figure 13a, exhibits a $-3 \mathrm{~dB}$ bandwidth of $350 \mathrm{kHz}$, which allows a data rate demodulation up to $200 \mathrm{~kb} / \mathrm{s}$. According to Equation (22), the RF to DC conversion gain is a function of the input signal amplitude $\mathrm{V}_{\mathrm{s}}$. This analysis holds for small input signals where the response is dominated by the second order term and higher order effects are not significant. The measured conversion gain, $\mathrm{GC}_{\mathrm{det}}$, is illustrated in Figure 13b. If the amplitude of the input signal is kept below $200 \mathrm{mV}, \mathrm{GC}_{\text {det }}$ is close to $0 \mathrm{~dB}$ and the expression (Equation (22)) gives a good approximation of it. If the amplitude is larger than $400 \mathrm{mV}$ the conversion gain rolls off, and the small signal analysis is no longer correct. To preserve the dynamic of demodulated data, the amplitude of the AM signal at the input of envelope detector would not exceed $500 \mathrm{mV}$.

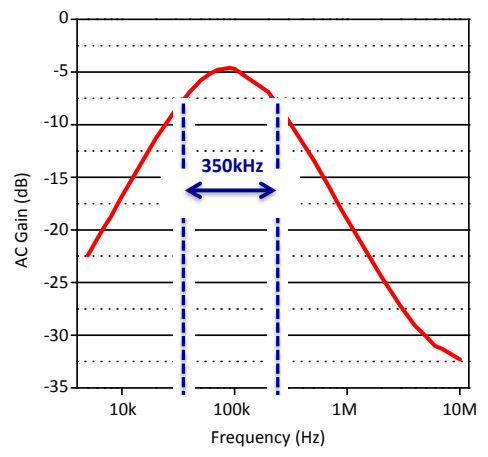

(a)

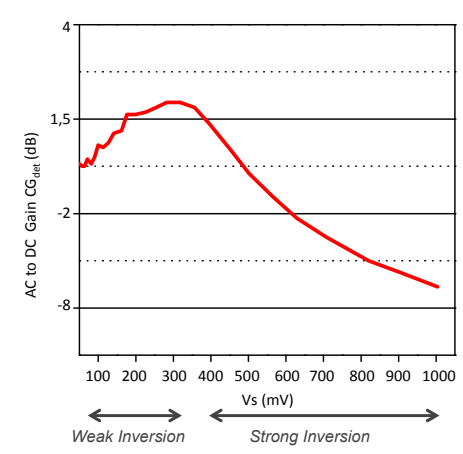

(b)

Figure 13. AC gain (a); $A C$ to $D C$ conversion gain $C_{\text {det }}$ versus the input amplitude $\mathrm{V}_{\mathrm{s}}(\mathbf{b})$ of the envelope detector. 


\section{Characterization of MOOD Demodulator}

A chip micrograph of the MOOD receiver proposed in Figure 7 is reported in Figure 14. The system was first tested with amplitude and frequency analog modulations. The measurement results are discussed in part 4.1. The response of MOOD receiver to a Frequency Shift Keying (FSK) modulated signal, and an On-Off Keying (OOK) modulated signal, is further exposed in part 4.2.

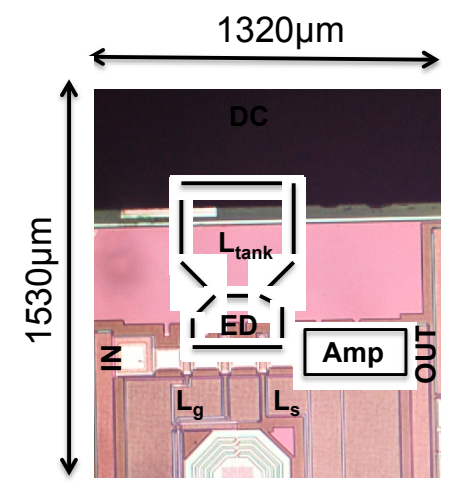

Figure 14. Chip micrograph of the MOOD receiver.

\subsection{Demodulation of Amplitude and Frequency Modulated Signals}

In the first set up, the modulating frequency $\mathrm{f}_{\mathrm{m}}$ and the carrier power level $\mathrm{P}_{\text {carrier }}$ are respectively fixed to $200 \mathrm{kHz}$ and $-12 \mathrm{dBm}$. The free running frequency, fol, is set to $2.48 \mathrm{GHz}$. The measured peakto-peak amplitude of the output voltage $\left(\mathrm{V}^{\mathrm{PP}}\right)$ at base band is reported in Figure 15a, for an amplitude modulated (AM) input signal, in Figure 15b, for a frequency modulated (FM) input signal.

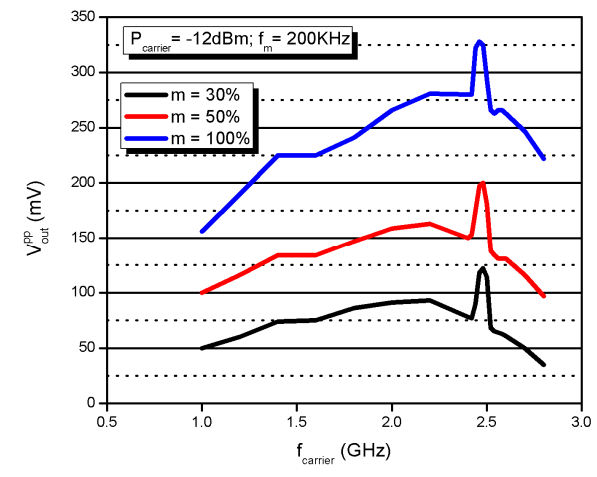

(a)

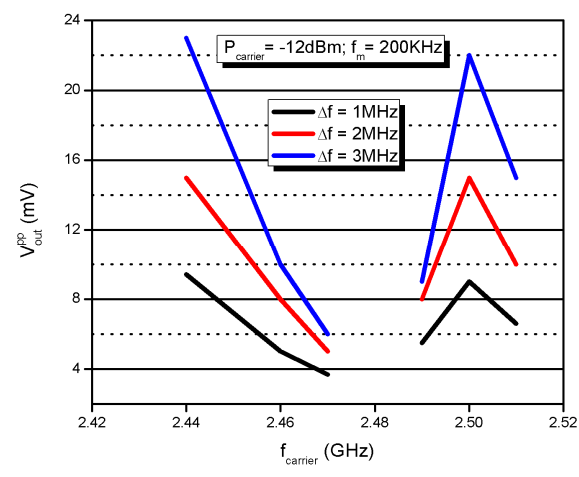

(b)

Figure 15. Peak-to-peak output voltage $\mathrm{V}^{\mathrm{PP}}$ versus carrier frequency for modulation depth ( $\mathrm{m}$ in \%) with an AM input signal (a); an FM input signal (b).

In Figure 15, we observe the amplitude of the output voltage $\mathrm{V}^{\mathrm{PP}}$ increases with the modulation depth for the two types of modulation. In the case of an AM signal, Figure 15a, the AM to AM conversion $\left(\mathrm{V}^{\mathrm{PP}}\right)$ smoothly increases as the carrier frequency gets closer to the free running frequency foL. When the oscillator is locked, dashed box in Figure 15a, the AM to AM transfer is maximum, the best efficiency yields at $\mathrm{m}=100 \%$ with a $\mathrm{V}^{\mathrm{PP}}$ of $350 \mathrm{mV}$, which corresponds to a voltage gain of $6 \mathrm{~dB}$. In the case of 
an FM input signal, Figure 15b, the frequency shift is converted into amplitude variation, we observe the amplitude of the output voltage $\mathrm{V}^{\mathrm{PP}}$ decreases as the carrier frequency gets closer to the free running frequency fol. When the oscillator is locked, dash box in Figure 15b, the frequency to amplitude conversion does not occur and $\mathrm{V}^{\mathrm{PP}}$ is zero, the FM signal is not demodulated.

The sensitivity of the receiver to the modulating frequency $\mathrm{f}_{\mathrm{m}}$ is illustrated in Figure 16 . The carrier frequency $\left(\mathrm{f}_{\text {carrier}}\right)$ and power $\left(\mathrm{P}_{\text {carrier }}\right)$ are fixed, the output amplitude $\mathrm{V}^{\mathrm{PP}}$ is measured for different $\mathrm{f}_{\mathrm{m}}$. For the AM test, the oscillator is locked to achieve a maximum AM-to-AM transfer. According to Figure $16 \mathrm{a}, \mathrm{V}^{\mathrm{PP}}$ is maximum if the $\mathrm{fm}_{\mathrm{m}}$ frequency is kept below $300 \mathrm{kHz}$. Above this frequency the demodulated signal is attenuated by the bandwidth of envelope detector. For the FM test, Figure 16b, the oscillator is operated in pulled mode, and the sensitivity is maximum for a $\mathrm{f}_{\mathrm{m}}$ of $380 \mathrm{kHz}$.

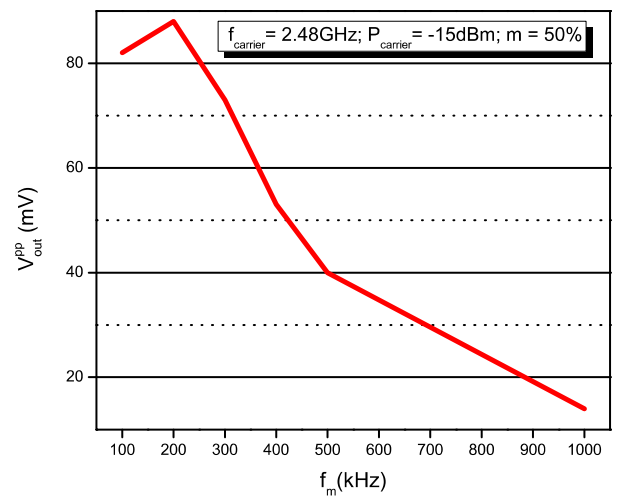

(a)

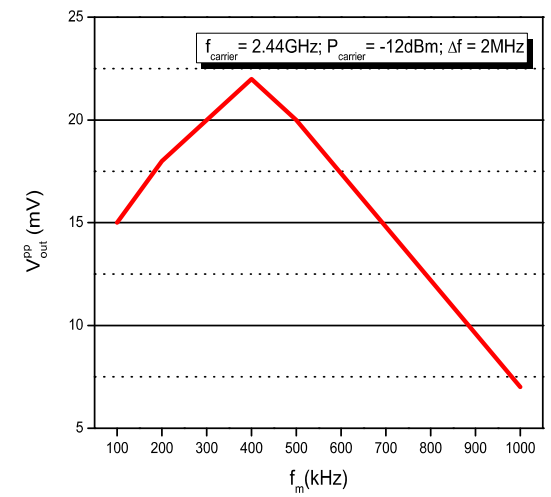

(b)

Figure 16. Peak-to-peak output voltage $\mathrm{V}^{\mathrm{PP}}$ versus the modulating frequency $\mathrm{f}_{\mathrm{m}}$ with an $\mathrm{AM}$ input signal (a); an FM input signal (b).

The test of the MOOD receiver with analog modulations confirms the investigations exposed in the Section 2. An AM signal is demodulated with a maximum efficiency when the oscillator is locked. A FM signal is demodulated on condition that the oscillator is in pulled mode.

\subsection{FSK and OOK Demodulation}

To complete the validation of the proposed demodulation concept, the MOOD receiver is tested with a pseudo random binary sequence. In Figure 17, the demodulated data are reported with the original data for different configurations of the AM input signal. In the two first test sets, Figure 17a,b, the data rate $\left(\mathrm{D}_{\mathrm{b}}\right)$ and carrier power $\left(\mathrm{P}_{\text {carrier}}\right)$ are respectively fixed to $20 \mathrm{kbps}$ and $-18 \mathrm{dBm}$, only the carrier frequency $\mathrm{f}_{\mathrm{RF}}$ changes. The amplitude of the demodulated data is larger in locked mode $8 \mathrm{mV}$, Figure 17a, compared to pulled mode $5 \mathrm{mV}$, Figure 17b. In Figure 17c the oscillator is locked, but the data rate is increased to $500 \mathrm{kbps}$. The wave form of the demodulated data is distorted by the cutoff frequency of the envelope detector. The bandwidth of the ED limits the maximum data rate in this case.

In Figure 18, the demodulated data are reported with the original data for different configurations of the FM input signal. Figure 18a illustrates the response of the receiver when the oscillator is locked. The FM signal is not demodulated. In Figure 18 b,c, the oscillator is in pulled mode, and the FM frequency shift $(\Delta \mathrm{f})$ is changed. For a small frequency shift, $100 \mathrm{kHz}$ in Figure 18b, the shape of the demodulated data is distorted, and the amplitude is small $(<1 \mathrm{mV})$. For a larger frequency shift, $1 \mathrm{MHz}$ 
in Figure 18c, the demodulated data exhibit a steep slope transition and the amplitude reaches $2 \mathrm{mV}$. Indeed, a large frequency shift is transformed into a large output voltage swing by the roll-off response of the oscillator. This analysis highlights the frequency to amplitude conversion is dependent to the quality factor of the LC tank.

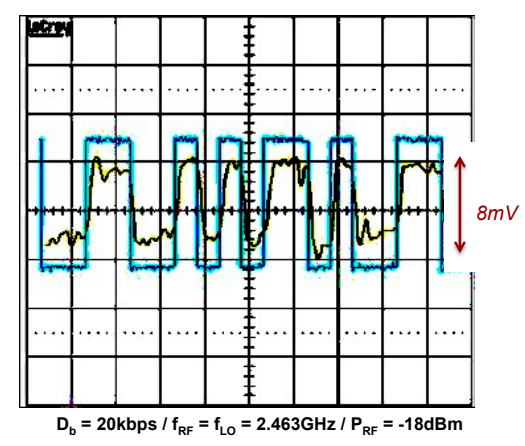

(a)

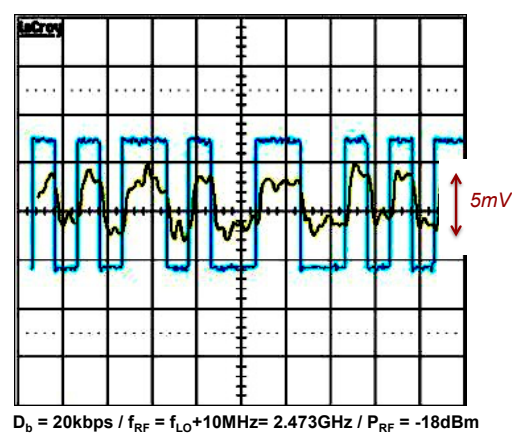

(b)

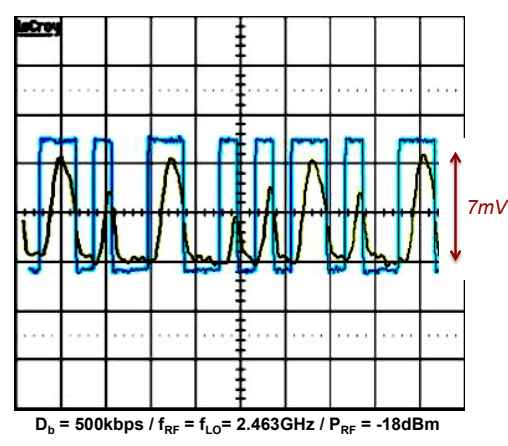

(c)

Figure 17. Demodulated data versus original data in locked mode at a data rate of $20 \mathrm{kbps}$ (a); in pulled mode at a data rate of $20 \mathrm{kbps}(\mathbf{b})$; in locked mode at a data rate of $500 \mathrm{kbps}(\mathbf{c})$.

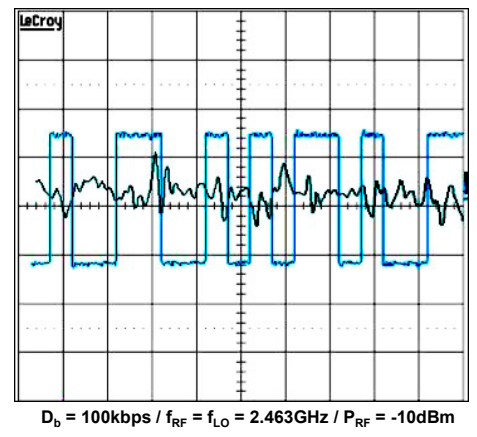

(a)

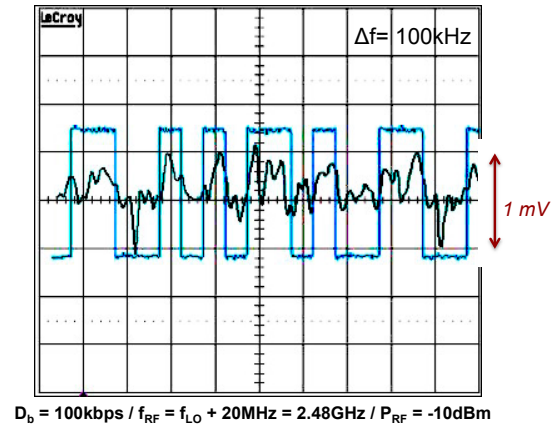

(b)

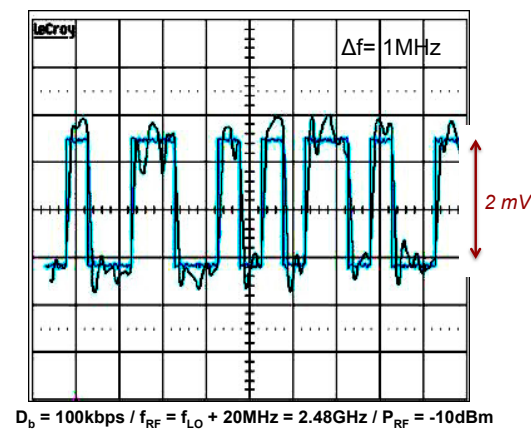

(c)

Figure 18. Demodulated data versus original data in locked mode (a); in pulled mode at a data rate of $100 \mathrm{kbps}$ and frequency shift $\Delta \mathrm{f}=100 \mathrm{kHz}(\mathbf{b})$; in pulled mode at a data rate of $100 \mathrm{kbps}$ and frequency shift $\Delta \mathrm{f}=1 \mathrm{MHz}(\mathbf{c})$.

The performances of the MOOD receivers are summarized in Table 1 . The sensitivity, $-36 \mathrm{dBm}$ for OOK mode, and $-27 \mathrm{dBm}$ for FSK mode, is measured when the output Signal to Noise Ratio (SNRout) reaches $12 \mathrm{~dB}$. This sensitivity can be significantly improved with the introduction of a Low Noise Amplifier before the MOOD circuit. The demodulators presented in [15,16], Table 1, do not use any active RF function, which drastically reduces the power consumption to respectively $0.1 \mu \mathrm{W}$ and $10 \mu \mathrm{W}$. To our knowledge, the demodulator presented in [15] exhibits the lowest power consumption reported in the literature. The introduction of a low noise amplification stage before the envelope detector, significantly improves the sensitivity as demonstrated in [4]. It also costs an extra power consumption of $40 \mu \mathrm{W}$. The receivers reported in $[4,15,16]$ are based on envelope detectors, which limit the compatibility to OOK modulated signals. The reference [17] proposes a WuRx dedicated to the demodulation of FSK. It features a digitally controlled oscillator coupled with an envelope detector. The power consumption is $45 \mu \mathrm{W}$, which is large with respect to the operating frequency $80 \mathrm{MHz}$, and 
compared to OOK solutions. The demodulation of an FSK signal requires RF functions that burden the power budget of the receiver.

The MOOD receiver proposed in this work does not really compete with Wu-Rx based on an unique envelope detector, in terms of power consumption and sensitivity, for the demodulation of a OOK signal only. However it is a low power solution for the demodulation of an FSK signal, which is also compatible with an OOK signal.

Table 1. Modulated oscillator for envelope detection (MOOD) performances and comparison with the state of the art.

\begin{tabular}{|c|c|c|c|c|c|c|}
\hline & \multicolumn{2}{|c|}{ This Work } & [15] & [4] & [16] & [17] \\
\hline Process & \multicolumn{2}{|c|}{$130 \mathrm{~nm}$} & $130 \mathrm{~nm}$ & $90 \mathrm{~nm}$ & $180 \mathrm{~nm}$ & $180 \mathrm{~nm}$ \\
\hline Frequency & \multicolumn{2}{|c|}{$2.4 \mathrm{GHz}$} & $915 \mathrm{MHz}$ & $2 \mathrm{GHz}$ & $2.4 \mathrm{GHz}$ & $80 \mathrm{MHz}$ \\
\hline Power Consumption & \multicolumn{2}{|c|}{$120 \mu \mathrm{W}$} & $0.1 \mu \mathrm{W}$ & $52 \mu \mathrm{W}$ & $10 \mu \mathrm{W}$ & $45 \mu \mathrm{W}$ \\
\hline VDD & \multicolumn{2}{|c|}{$0.6 \mathrm{~V}$} & $1.2 \mathrm{~V}$ & $0.5 \mathrm{~V}$ & $0.5 \mathrm{~V}$ & $0.7 \mathrm{~V}$ \\
\hline Modulation & OOK & FSK & OOK & OOK & OOK & FSK \\
\hline Data rate & $150 \mathrm{kbps}$ & $300 \mathrm{kbps}$ & $100 \mathrm{kbps}$ & $100 \mathrm{kbps}$ & $100 \mathrm{kbps}$ & $300 \mathrm{kbps}$ \\
\hline Sensitivity & $-36 \mathrm{dBm}$ & $-27 \mathrm{dBm}$ & $-41 \mathrm{dBm}$ & $-72 \mathrm{dBm}$ & $-65 \mathrm{dBm}$ & $-62 \mathrm{dBm}$ \\
\hline
\end{tabular}

\section{Conclusions}

The deployment of WSNs are critical for the development of IOT. Among the tough challenges in the implementation of dense WSNs are: the reduction of the power consumption dedicated to wireless communications, and the interoperability of the networks. To address these challenges, an ultra low power demodulator compatible with the two most common modulation schemes exploited in WSNi.e., OOK and FSK - is proposed in this work.

The principle of demodulation is based on a frequency to amplitude conversion, performed by an LC oscillator optimized for low power consumption, and combined with an envelope detector, namely MOOD demodulators. The optimum conditions of operation of an MOOD demodulator are theoretically investigated and then verified with measurement results. Hence, the demodulation of an AM signal is improved when the oscillator is locked to the carrier frequency, where as the FM demodulation only occurs when the oscillator is in pulled mode. A proof of concept is implemented in a $65 \mathrm{~nm}$ CMOS technology and is intended for $2.4 \mathrm{GHz}$ ISM Band. The measurement results of the MOOD demodulator demonstrate its ability to properly demodulate FSK and OOK modulated signals for a power budget of only $120 \mu \mathrm{W}$ at a data rate of $100 \mathrm{kbps}$ and a sensitivity close to $-30 \mathrm{dBm}$.

\section{Acknowledgements}

The authors would like to acknowledge M. De Matos for her support in measurement results.

\section{Conflicts of Interest}

The authors declare no conflict of interest 


\section{References}

1. Lin, E.Y.; Rabaey, J.; Wolisz, A. Power-efficient rendezvous schemes for dense wireless sensor networks. Proc. IEEE Int. Conf. Commun. 2004, 7, 3769-3776.

2. Vidojkovic, M.; Rampu, S.; Imamura, K.; Harpe, P.; Dolmans, G.; de Groot, H. A $500 \mu$ W 5 Mbps ULP super-regenerative RF Front-End In Proceedings of the IEEE Solid-State Circuits Conference Digest of Technical Papers, San Francisco, CA, USA, 7-11 February 2010; pp. 222-223.

3. Huang, X.; Rampu, S.; Xiaoyan Wang; Dolmans, G.; de Groot, H. A 2.4 GHz/915 MHz $51 \mu \mathrm{W}$ wake-up receiver with offset and noise suppression. In Proceedings of the European Solid State Circuits Conference, Seville, Spain, 13-17 September 2010; pp. 462-475.

4. Pletcher, N.; Gambini, S.; Rabaey, J.M. A 2 GHz $52 \mu \mathrm{W}$ Wake-Up Receiver with $-72 \mathrm{dBm}$ Sensitivity Using Uncertain-IF Architecture. IEEE J. Solid State Circuits 2009, 44, 269-280.

5. Lont, M.; Milosevic, D.; van Roermund, A.H.M.; Dolmans, G. Ultra-Low Power FSK Wake-up Receiver Front-End for Body Area Networks. In Proceedings of the IEEE Radio-Frequency Integrated Circuit Symposium, Baltimore, MD, USA, 5-7 June 2011; pp.1-4.

6. Razavi, B. A study of injection locking and pulling in oscillators. IEEE J. Solid State Circuits 2004, 39, 1415-1424.

7. Adler, R. A study of locking phenomena in oscillators. Proc. IEEE 1973, 61, 1380-1385.

8. Kurokawa, K. Injection locking of microwave solid-state oscillators. Proc. IEEE 1973, 61, 1386-1410.

9. Paciorek, L.J. Injection locking of oscillators. Proc. IEEE 1965, 53, 1723-1727.

10. Stover, H.L. Theoretical explanation for the output spectra of unlocked driven oscillators. Proc. IEEE 1966, 54, 310-311.

11. Armand, M. On the output spectrum of unlocked driven oscillators. Proc. IEEE 1969, 57, 798-799.

12. Pletcher, N.M. Ultra-low power wake-up receivers for Wireless Sensor Networks. Ph.D. Thesis, University of California, Berkeley, CA, USA, May, 2008.

13. Meyer, R.G. Low-power monolithic RF peak detector analysis. IEEE J. Solid State Circuits 1995, 30, 65-67.

14. Gray, P.R. Analysis and Design of Analog Integrated Circuits; John Wiley \& Sons: Hoboken, NJ, USA, 2009.

15. Roberts, N.E.; Wentzloff, D.D.A $98 \mathrm{nW}$ Wake-Up Radio for Wireless Body Area Networks. In Proceedings of the IEEE Radio Frequency Integrated Circuits Symposium, Montreal, QC, Canada, 17-19 June 2012; pp. 373-376.

16. Cheng, K.W.; Liu, X.; Je, M. A $2.4 / 5.8 \mathrm{GHz} 10 \mu \mathrm{W}$ Wake-Up Receiver woth $-65 /-50 \mathrm{dBm}$ Sensitivity using direct active RF detection. In Proceeding of the IEEE Asian Solid-State Circuits Conference, Kobe, Japan, 12-14 November 2012; pp. 337-340.

17. Bae, J.; Yoo, H.J. A $45 \mu \mathrm{W}$ Injected Locked FSK Wake-Up Receiver with Frequency-to-Envelope Conversion for Crystal-less Wireless Body Area Network. IEEE J. Solid-State Circuits 2015, 50, 1351-1360.

(C) 2015 by the authors; licensee MDPI, Basel, Switzerland. This article is an open access article distributed under the terms and conditions of the Creative Commons Attribution license (http://creativecommons.org/licenses/by/4.0/). 